\title{
Modeling the linear viscoelastic behavior of asphaltite-modified bitumens
}

\section{Andrea Themeli, Emmanuel Chailleux, Fabienne Farcas, Cyrille Chazallon, Bernard Migault \& Nadège Buisson}

\section{Rheologica Acta}

ISSN 0035-4511

Rheol Acta

DOI 10.1007/s00397-016-0968-x

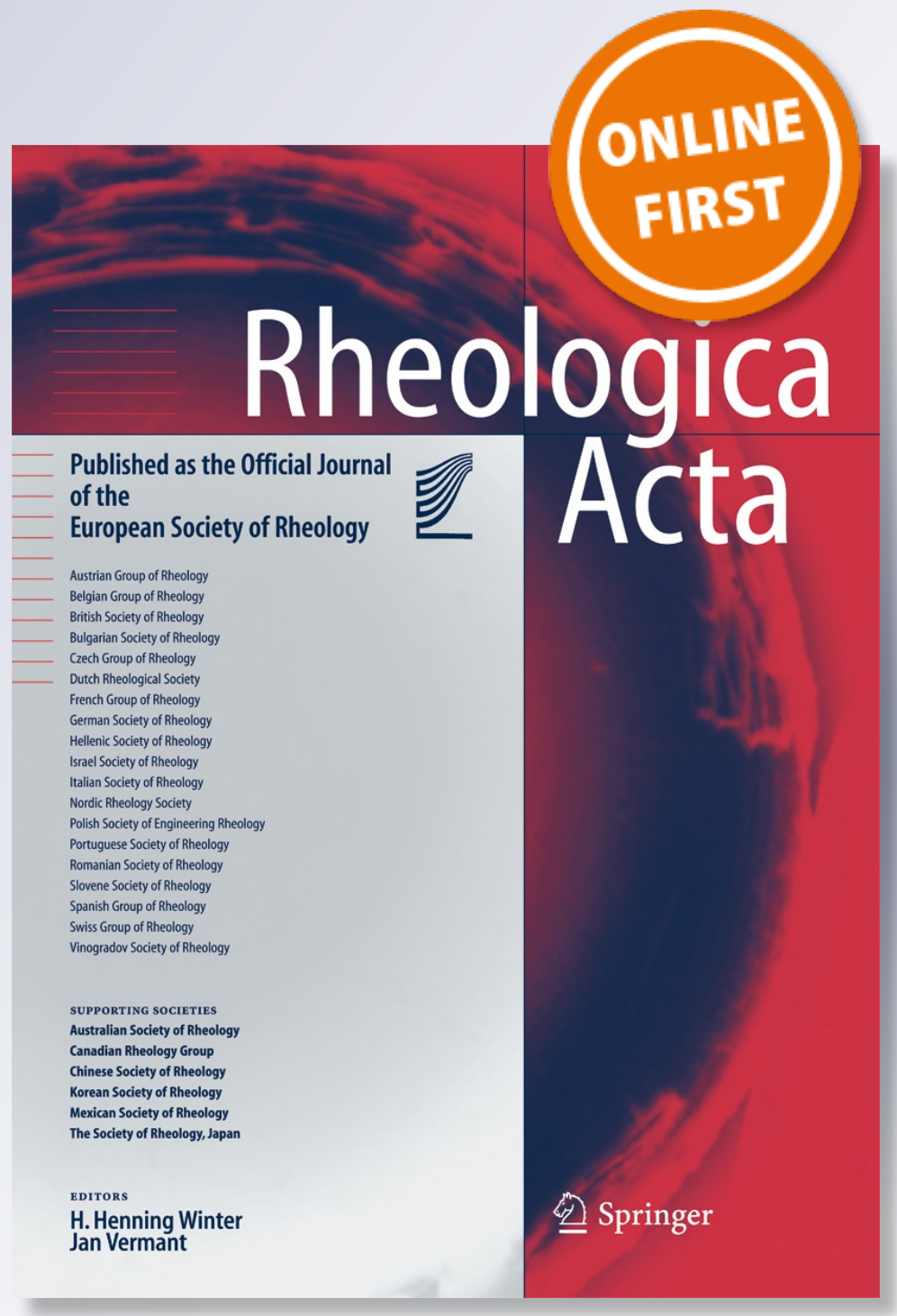

Springer 
Your article is protected by copyright and all rights are held exclusively by SpringerVerlag Berlin Heidelberg. This e-offprint is for personal use only and shall not be selfarchived in electronic repositories. If you wish to self-archive your article, please use the accepted manuscript version for posting on your own website. You may further deposit the accepted manuscript version in any repository, provided it is only made publicly available 12 months after official publication or later and provided acknowledgement is given to the original source of publication and a link is inserted to the published article on Springer's website. The link must be accompanied by the following text: "The final publication is available at link.springer.com". 


\title{
Modeling the linear viscoelastic behavior of asphaltite-modified bitumens
}

\author{
Andrea Themeli ${ }^{1,2,3,4}$ (1) Emmanuel Chailleux ${ }^{2} \cdot$ Fabienne Farcas ${ }^{3}$. \\ Cyrille Chazallon $^{1} \cdot$ Bernard Migault $^{1} \cdot$ Nadège Buisson $^{2}$
}

Received: 29 April 2016/Revised: 25 August 2016/Accepted: 13 September 2016

(C) Springer-Verlag Berlin Heidelberg 2016

\begin{abstract}
A modeling approach which allows predicting the linear viscoelastic behavior of bitumen blends from the linear viscoelastic properties of individual constituents is presented in this paper. This approach consists in a combination of the Tsenoglou rule for miscible viscoelastic materials with the Palierne model for viscoelastic emulsions. Based on some simple assumptions, this combination predicts satisfactorily the rheological behavior of asphaltite-modified bitumens and, consequently, it can be used for dosage purposes. Beyond asphaltite-modified bitumens, the modeling approach developed here can be applied on reclaimed asphalt-modified bitumens, polymer-modified bitumens, and on blends of partially miscible polymers presenting a suspended droplet morphology.
\end{abstract}

Keywords Bitumen blends - Modified bitumen - Asphaltite Linear viscoelasticity $\cdot$ Partially miscible blends

Electronic supplementary material The online version of this article (doi:10.1007/s00397-016-0968-x) contains supplementary material, which is available to authorized users.

Andrea Themeli

andrea.themeli@yahoo.com

Emmanuel Chailleux

emmanuel.chailleux@ifsttar.fr

1 ICUBE (UMR 7357, CNRS, National Institute of Applied Sciences), Strasburg, France

2 Laboratory of Transport Infrastructures Materials, Materials and Structures Department, IFSTTAR-Nantes, Nantes, France

3 Laboratory of Materials Physicochemistry, Materials and Structures Department, IFSTTAR-Marne La Vallée, Marne La Vallée, France

4 EPSILON Ingénierie, Anse, France

\section{Introduction}

The study of bitumen blends is of a real interest nowadays. The increasing use of recycled asphalts (Al-Qadi et al. 2007), natural asphalts, and different polymer modifiers (Bardesi et al. 1999) in combination with pure petroleum bitumens demands new calculation methods for predicting the rheological behavior of blends and enabling the formulation of new materials with requested properties.

Depending on constituents, the blends can be miscible, as it is the case of blends of petroleum bitumens of similar consistencies (Soleymani et al. 1999, Whiteoak 1990) or immiscible, as it is the case of polymer-modified bitumens which present distinct phases (Lesueur 2009). If the blending conditions of bitumens are favorable (low blending temperature, short blending time), partial miscibility (a certain quantity of component $\mathrm{A}$ is combined with component $\mathrm{B}$ and viceversa) can be suspected, especially if the difference in viscosity between the two blended bitumens is important.

A large variety of rheological modeling approaches can be found in the literature for blends of miscible materials (Des Cloizeaux 1990, Doi \& Edwards 1986, Groves et al. 1996, Haley \& Lodge 2004, Soleymani et al. 1999, Tsenoglou 1987, Tsenoglou 1988a,b, Tsenoglou 1991) and blends of immiscible materials (Bousmina 1999, Choi \& Schowalter 1975, Frohlich \& Sack 1946, Kerner 1956, Oldroyd 1953, 1955, Palierne 1990, 1991, Taylor 1932).

In the case of miscible components, the microstructure can be considered as homogeneous at the molecular level. Instead, immiscible components, depending on interfacial properties, mixing protocols, and volume fraction of phases, may generate different structural organizations as cocontinuous morphologies or suspended droplet-type systems (Ton-That et al. 2001). For immiscible systems, the morphological information (structural organization type, phase 
quantities, droplet form, droplet size distribution, etc.) is input to the rheological models when the prediction of rheological properties is required (Bousmina \& Muller 1993, Brahimi et al. 1991, Graebling et al. 1994, Graebling et al. 1993, Palierne 1990). In this case, the morphological properties should be established preliminarily by means of any microscopy techniques. For the study of bitumens and petroleum products, different techniques like atomic force microscopy (Loeber et al. 1996), small angle X-ray scattering and neutron scattering (Dwiggins 1965, Henaut et al. 2001, Overfield et al. 1989, Ravey et al. 1988), scanning electron microscopy (Loeber et al. 1996), confocal laser scanning microscopy (Bearsley et al. 2004, Florian et al. 2014, Lu et al. 2005), and microscopy under UV light (Lesueur et al. 1998, Soenen et al. 2008) are employed. Inversely, rheological measurements are often used to deduce the morphological features of the system (Friedrich et al. 1995, Roths et al. 2002, Vinckier et al. 1997, Vinckier et al. 1996), especially when it is difficult or impossible to establish them by other techniques.

In the framework of a wide research project, the potential of asphaltites as modifiers of petroleum bitumens was studied (Themeli 2015, Themeli et al. 2016). The asphaltites used in this study are very hard natural bitumens (zero penetration and softening point $>120{ }^{\circ} \mathrm{C}$ ), with a high content of polar constituents (resins + asphaltenes $\approx 75 \%$ ). In the case of our asphaltitemodified bitumens, the visualization of the blended components by microscopy techniques is impossible due to lack of contrast between the two materials. For this reason, we are not able to define the degree of miscibility between the asphaltite and the pure petroleum bitumen (miscible, partially miscible, or immiscible) and no morphological features can be established. In this context, for the purposes of our modeling, we assume an initial emulsion-type system of asphaltite droplets dispersed in the petroleum bitumen matrix. In addition, we assume that during the modifying process, the asphaltite gradually solubilizes into the petroleum bitumen and the system gradually evolves from an emulsion type into a miscible system. This kinetics seems to be logical and in order to model it at least two rheological approaches, one for immiscible systems and one for miscible ones, are necessary. We have chosen the Dickie variant (Dickie 1973) of the Palierne model for viscoelastic emulsions (Palierne 1990) and the Tsenoglou combination rule for miscible systems (Tsenoglou 1991). The Tsenoglou combination rule was chosen because, as it is shown later on in this paper, classic mixing rules traditionally used for bitumen blends were unable to model correctly our experimental data.

In this paper, the classic blending law, traditionally used in the bitumen science, is presented in a first time.
The Palierne model and the Tsenoglou combination rule are presented afterwards. Then, these models are applied to experimental results collected on asphaltite/petroleumbitumen blends. Finally, in order to model the modification kinetics and allow the prediction of blends' linear viscoelastic behavior, a combination of both models is proposed.

\section{Review of some rheological modeling approaches}

In the following paragraphs, different approaches for modeling the linear viscoelastic behavior of blends based on the behavior of pure components are presented. The domain of rheological modeling of blended materials is large but we have limited our discussion to models which seem more appropriate to bitumens. First, the classic blending law, traditionally used for bitumen blends, is presented. Then, other rheological models, largely employed in polymer science; the Tsenoglou combination rule for blends of miscible materials; and the Palierne model for viscoelastic emulsions are detailed. We have also considered, but not detailed here, two other modeling approaches: a self-consistent approach (Hadrzynski \& Such, 1998) and a second approach based on analogical elements (Mangiafico et al. 2014) which, for our asphaltite-modified bitumens, have not given satisfactory results.

\section{Classic blending laws}

The consistency of bitumens is characterized by two empirical tests: the penetration test and the softening point test carried out according to norms EN-1427 and EN-1426, respectively. Classic blending laws are used often for the prediction of the penetration, and the softening point of bitumen blends form the respective properties of pure components $\mathrm{A}$ and $\mathrm{B}$ (Whiteoak 1990, Widyatmoko \& Elliott 2008):

$\log \left(P_{b}\right)=x \cdot \log \left(P_{A}\right)+(1-x) \cdot \log \left(P_{B}\right)$

$\mathrm{SP}_{b}=x \cdot \mathrm{SP}_{A}+(1-x) \cdot \mathrm{SP}_{B}$

with:

$P_{b}, P_{A}, P_{B} \quad$ Penetrations of blend, component $\mathrm{A}$ and component B, respectively

$S P_{b}, S P_{A}, \quad$ Softening points of blend, component $\mathrm{A}$ and

$S P_{B} \quad$ component $\mathrm{B}$, respectively

$x \quad$ Mass rate of component $\mathrm{A}$ in the blend

Soleymani et al. making the assumption that a linear relationship exists between the linear viscoelastic 
properties of bitumen blends and the ratios of components in the blend, extended the use of the classic blending laws in the prediction of the linear viscoelastic properties (Soleymani et al. 1999):

$\log \left|E_{b}^{*}(\omega, T)\right|=x \cdot \log \left|E_{A}^{*}(\omega, T)\right|+(1-x) \cdot \log \left|E_{B}^{*}(\omega, T)\right|$

$\delta_{b}(\omega, T)=x \cdot \delta_{A}(\omega, T)+(1-x) \cdot \delta_{B}(\omega, T)$

with:

$\left|E_{b}^{*}\right|,\left|E_{A}^{*}\right|, \quad$ Complex modulus norms of blend,

$\left|E_{B}^{*}\right| \quad$ component $\mathrm{A}$ and component $\mathrm{B}$, respectively

$\delta_{b}, \delta_{A}, \delta_{B} \quad$ Phase angle of blend, component A and component $\mathrm{B}$, respectively

$x \quad$ The mass rate of component $\mathrm{A}$ in the blend

The authors applied Eqs. 3 and 4 to rheological measurements performed on blends of reclaimed bitumens with pure petroleum bitumen, and they found that the predictions were accurate for components of similar consistency. However, they have reported important deviations from the classic blending law if the two components present very different viscoelastic properties (Soleymani et al. 1999).

\section{Tsenoglou combination rule for miscible blends}

Tsenoglou developed a rheological model in order to explain the linear viscoelastic behavior of miscible heteropolymer blends and that of homopolymer blends of dissimilar molecular weights (Tsenoglou 1987, Tsenoglou 1988a, b, Tsenoglou 1991). This model or variants of it are often used to interpret linear viscoelastic data issued from miscible polymer melts (Gell et al. 1997, Groves et al. 1996, Haley et al. 2003). The model is based on the assumption that the coupling probability between any two components along a single chain is proportional to the fractional participation of each component in the blend which yields to the following relaxation modulus for the blend:

$G_{b}(t)=\left[\sum_{i=1}^{n} \phi_{i} \cdot G_{i}(t)^{1 / 2}\right]^{2}$

where $\phi_{i}$ and $G_{i}(t)$ are the volume fraction and the relaxation modulus of the $i^{\text {th }}$ component and $n$ the number of components in the blend.

Approximating the relaxation function of each component in the blend with a single exponential term, and introducing these approximations to Eq. 5, the storage and loss moduli of the blend were calculated and expressed in terms of components' properties and fractions as follows (Tsenoglou 1991):

$G_{b}^{\prime}(\omega) \cong \sum_{i}^{n} \sum_{j}^{n}\left(G_{N i}\right)^{\frac{1}{2}}\left(G_{N j}\right)^{\frac{1}{2}} \phi_{i} \phi_{j}\left[1+\frac{1}{4}\left(\left(\frac{G_{N i}}{G_{i}^{\prime}(\omega)}-1\right)^{\frac{1}{2}}+\left(\frac{G_{N j}}{G_{j}^{\prime}(\omega)}-1\right)^{\frac{1}{2}}\right)^{2}\right]^{\frac{1}{2}}$

$G_{b}^{\prime \prime}(\omega) \cong \sum_{i=1}^{n} \sum_{j=1}^{n}\left(G_{N i}\right)^{\frac{1}{2}} \cdot\left(G_{N j}\right)^{\frac{1}{2}} \cdot \phi_{i} \cdot \phi_{j} \cdot\left(G_{i j}+\frac{1}{G_{i j}}\right)^{-1}$

with : $G_{i j}=\frac{G_{N i}-G_{i}^{\prime}(\omega)}{2 G_{i}^{\prime \prime}(\omega)}+\frac{G_{N j}-G_{j}^{\prime}(\omega)}{2 G_{j}^{\prime \prime}(\omega \cdot)}$

where $G_{N}$ denotes the plateau modulus. For binary blends where both components have equal plateau moduli and where $G_{N} \gg G^{\prime}$ and $G^{\prime \prime}$, Eqs. 6 and 7 are reduced to:

$$
\begin{aligned}
& G_{b}^{\prime}(\omega) \cong \phi_{1}^{2} \cdot G_{1}^{\prime}(\omega)+\phi_{2}^{2} \cdot G_{2}^{\prime}(\omega) \\
& +\frac{8 \cdot \phi_{1} \cdot \phi_{2} \cdot G_{1}^{\prime}(\omega) \cdot G_{2}^{\prime}(\omega)}{G_{1}^{\prime}(\omega)+2 \cdot G_{1}^{\prime}(\omega)^{\frac{1}{2}} \cdot G_{2}^{\prime}(\omega)^{\frac{1}{2}}+G_{2}^{\prime}(\omega)} \\
& G_{b}^{\prime \prime}(\omega) \cong \phi_{1}^{2} \cdot G_{1}^{\prime \prime}(\omega)+\phi_{2}^{2} \cdot G_{2}^{\prime \prime}(\omega)+\frac{4 \cdot \phi_{1} \cdot \phi_{2} \cdot G_{1}^{\prime \prime}(\omega) \cdot G_{2}^{\prime \prime}(\omega)}{G_{1}^{\prime \prime}(\omega)+G_{2}^{\prime \prime}(\omega)}
\end{aligned}
$$

The assumption of an exponential relaxation function, which is correct for monodisperse systems, remains critical for bitumens. However, the model has given satisfactory prediction results on mixtures of highly polydisperse components (Lee \& Denn 2000). In addition, as we will see in the discussion section hereafter, the Tsenoglou combination rule gives satisfactory modeling of the bitumen blends for a wide range of temperatures.

The Tsenoglou model assumes that the components have similar glass transitions. When the glass transition temperatures of the components are very different, the monomeric frictions of the components in the mixed state are different from those in the pure state at the same temperature. This difference comes from the change of the effective glass transition temperatures of the components in the mix. This difference is commonly compensated by introducing into the calculations the dynamic moduli of each component measured at the same temperature from the effective glass transition temperature (Gell et al. 1997).

The Tsenoglou model is conceived by considering the network architecture of entangled polymers in the blend. However, the treatment is also valid when some of the blend components are oligomers or regular solvents (Tsenoglou 1988a). In this study, we have applied the Tsenoglou model, for the first time to our knowledge, to bitumens which show viscoelastic behavior (Brodnyan et al. 1960) and can be 
considered as low molecular weight natural polymers with a degree of polymerization, deduced from differential scanning calorimetry, around 10 (Masson \& Polomark 2001).

\section{Palierne model for immiscible blend}

Palierne developed a model for the calculation of the linear viscoelastic behavior of emulsions of viscoelastic incompressible fluids (Palierne 1990). This model is the generalization of previous works of Einstein on the viscosity of dilute suspensions of rigid spheres in a Newtonian matrix, Frohlich and Sack on the viscoelasticity of dilute suspension of elastic deformable spheres in a Newtonian matrix (Frohlich \& Sack 1946), Taylor and Oldroyd on the viscoelasticity of dilute emulsions of Newtonian drops in a Newtonian matrix (Oldroyd 1953, 1955, Taylor 1932), Choi and Schowalter for semi-dilute emulsions of Newtonian drops in a Newtonian matrix (Choi \& Schowalter 1975), and of Kerner on the elastic behavior of a composite of Hookean spheres dispersed in a Hookean matrix (Kerner 1956), which are particular cases of the Palierne model.

The model considers viscoelastic spherical inclusions, with arbitrary size distribution, dispersed in a viscoelastic matrix in dilute and semi-dilute regimes. The mechanical contribution of the interfacial tension between the phases is taken into account. The interactions between particles are considered by averaging the complex shear modulus of the medium by a self-consistent treatment. In its general form, the Palierne model for the dilute regime $\left(\sum_{i} \phi_{i}<10 \%\right)$ is:

$\mathrm{G}_{b}^{*}=G_{M}^{*}\left(1+2.5 \sum_{i} \frac{E_{i}^{*}}{D_{i}^{*}} \phi_{i}\right)$

and for the semi-dilute regime is:

$$
\mathrm{G}_{b}^{*}=G_{M}^{*} \frac{1+1.5 \sum_{i} \frac{E_{i}^{*}}{D_{i}^{*}} \phi_{i}}{1-\sum_{i} \frac{E_{i}^{*}}{D_{i}^{*}} \phi_{i}}
$$

where:

$$
\begin{aligned}
E_{i}^{*}= & 2\left(G_{I}^{*}-G_{M}^{*}\right)\left(19 G_{I}^{*}+16 G_{M}^{*}\right)+48 \frac{\beta^{\prime} \alpha}{R^{2}} \\
& +32 \beta^{\prime \prime} \frac{\left(\alpha+\beta^{\prime}\right)}{R^{2}}+8 \frac{\alpha}{R}\left(5 G_{I}^{*}+2 G_{M}^{*}\right) \\
& +2 \frac{\beta^{\prime}}{R}\left(23 G_{I}^{*}-16 G_{M}^{*}\right)+4 \frac{\beta^{\prime \prime}}{R}\left(13 G_{I}^{*}+8 G_{M}^{*}\right)
\end{aligned}
$$

and

$$
\begin{aligned}
D_{i}^{*}= & \left(2 G_{I}^{*}+3 G_{M}^{*}\right)\left(19 G_{I}^{*}+16 G_{M}^{*}\right)+48 \frac{\beta^{\prime} \alpha}{R^{2}} \\
& +32 \beta^{\prime \prime} \frac{\left(\alpha+\beta^{\prime}\right)}{R^{2}}+40 \frac{\alpha}{R}\left(G_{I}^{*}+G_{M}^{*}\right) \\
& +2 \frac{\beta^{\prime}}{R}\left(23 G_{I}^{*}+32 G_{M}^{*}\right)+4 \frac{\beta^{\prime \prime}}{R}\left(13 G_{I}^{*}+12 G_{M}^{*}\right)
\end{aligned}
$$

with:

$\mathrm{G}_{b}^{*}, \quad$ Complex moduli of blend, of matrix, and of

$G_{M}^{*}, G_{I}^{*} \quad$ dispersed inclusions, respectively

$\phi_{i} \quad$ Volume fraction of the dispersed particles of radius $R_{i}$

$\alpha \quad$ Static, isotropic part of the interfacial tension

$\beta^{\prime}(\omega) \quad$ Harmonic, isotropic part of the interfacial tension related to the variation of the interface area (elongation modulus of the interface)

$\beta^{\prime \prime}(\omega) \quad$ Harmonic, non-isotropic part of the interfacial tension related to the shear of the interface without area variation (shear modulus of the interface)

The model is extensively used in the literature for the prediction of the linear viscoelastic behavior of polymer blends (Bousmina \& Muller 1993, Brahimi et al. 1991, Friedrich et al. 1995, Graebling et al. 1993), for the determination of their interfacial tension or morphological features (Graebling et al. 1993, Graebling \& Muller 1990, Graebling \& Muller 1990, Kim et al. 1993, Lacroix et al. 1996, Riemann et al. 1996, 1997, Van Hemelrijck et al. 2004), or for the study of the mechanical contribution of additions of interfacial agents (Jacobs et al. 1999, Riemann et al. 1997). Applied to polymer-modified bitumens, it gives an interfacial tension $\alpha \approx 10 \mu \mathrm{N} / \mathrm{m}$ (Lesueur et al. 1998). It was never used, however, to study bitumen blends.

The harmonic parts of the interfacial tension are generally neglected in the literature. Considering a biphasic monodisperse system with null $\beta^{\prime}(\omega)$ and $\beta^{\prime \prime}(\omega)$, the Palierne model for the semi-dilute regime reduces to:

$G_{b}^{*}=G_{M}^{*} \frac{1+3 \phi H(\omega)}{1-2 \phi H(\omega)}$

where:

$H(\omega)=\frac{4 \frac{\alpha}{R}\left[2 G_{M}^{*}+5 G_{I}^{*}\right]+\left[G_{I}^{*}-G_{M}^{*}\right]\left[16 G_{M}^{*}+19 G_{I}^{*}\right]}{40 \frac{\alpha}{R}\left[G_{M}^{*}+G_{I}^{*}\right]+\left[2 G_{I}^{*}+3 G_{M}^{*}\right]\left[16 G_{M}^{*}+19 G_{I}^{*}\right]}$ 
Table 1 Materials

\begin{tabular}{|c|c|}
\hline Reference & Description \\
\hline $\mathrm{P} 50 / 70$ & 50/70 grade paraffinic petroleum bitumen \\
\hline NP50/70 & 50/70 grade non-paraffinic petroleum bitumen \\
\hline $\mathrm{P} 35 / 50$ & $35 / 50$ grade paraffinic petroleum bitumen \\
\hline TAD & Organic phase of treated asphaltite mined in deep layers of the mine \\
\hline $95 \% \mathrm{P} 50 / 70+5 \% \mathrm{TAD}$ & $50 / 70$ grade paraffinic bitumen modified with $5 \%$ of asphaltite \\
\hline $90 \% \mathrm{P} 50 / 70+10 \% \mathrm{TAD}$ & $50 / 70$ grade paraffinic bitumen modified with $10 \%$ of asphaltite \\
\hline $85 \% \mathrm{P} 50 / 70+15 \% \mathrm{TAD}$ & $50 / 70$ grade paraffinic bitumen modified with $15 \%$ of asphaltite \\
\hline $95 \% \mathrm{NP} 50 / 70+5 \% \mathrm{TAD}$ & $50 / 70$ grade non-paraffinic bitumen modified with $5 \%$ of asphaltite \\
\hline $90 \% \mathrm{NP} 50 / 70+10 \% \mathrm{TAD}$ & $50 / 70$ grade non-paraffinic bitumen modified with $10 \%$ of asphaltite \\
\hline $85 \%$ NP50/70 + $15 \%$ TAD & $50 / 70$ grade non-paraffinic bitumen modified with $15 \%$ of asphaltite \\
\hline $95 \% \mathrm{P} 35 / 50+5 \% \mathrm{TAD}$ & $35 / 50$ grade paraffinic bitumen modified with $5 \%$ of asphaltite \\
\hline $90 \% \mathrm{P} 35 / 50+10 \% \mathrm{TAD}$ & $35 / 50$ grade paraffinic bitumen modified with $10 \%$ of asphaltite \\
\hline
\end{tabular}

If, further, the static isotropic component of the interfacial tension, $\alpha$, is set to 0 , then the generalization of the Kerner model, for elastic composites, to viscoelasticity is obtained, which corresponds to the Dickie's result (Dickie 1973):

$G_{b}^{*}=G_{M}^{*} \frac{\left[2 G_{I}^{*}+3 G_{M}^{*}\right]+3 \phi\left[G_{I}^{*}-G_{M}^{*}\right]}{\left[2 G_{I}^{*}+3 G_{M}^{*}\right]-2 \phi\left[G_{I}^{*}-G_{M}^{*}\right]}$

\section{Materials and experiments}

\section{Materials}

All the materials considered in this study are presented in Table 1.

Three petroleum bitumens are considered. Two of them belong to the same penetration grade $(50 / 70)$ but have different chemical natures. The third one has the same chemical nature as the first one but belongs to a harder grade $(35 / 50)$.

The asphaltite used in this study is mined in Albania in the region of Selenizza. In its natural state, this asphaltite contains $15-20 \%$ of mineral matter. Its organic phase, which is used in the present study to modify the petroleum bitumens, is isolated by dissolution in tetrachloroethylene and filter centri fugation.

The modifying process consists in adding the grinded organic phase of asphaltite $(\varnothing<1 \mathrm{~mm})$ in the preheated $\left(180{ }^{\circ} \mathrm{C}\right)$ petroleum-bitumen base and mixing with a high shear mixer for $1 \mathrm{~h}$ at $180{ }^{\circ} \mathrm{C}$. Modification rates of 5,10 , and $15 \%$ were chosen in order to obtain 35/ 50, 20/30, and 10/20 grade bitumens, respectively. Eight modified bitumens were prepared (Table 1).

\section{Experiments and results}

\section{Complex modulus}

Rheological properties in terms of complex modulus in the linear domain are determined by oscillatory rheological tests carried out on a viscoanalyser METRAVIB. Annular shearing (on rings of $h=5 \mathrm{~mm}, D=10 \mathrm{~mm}$, $d=8 \mathrm{~mm}$ ) and traction-compression (on cylinders of $D=9 \mathrm{~mm}, h=18 \mathrm{~mm}$ for pure and modified bitumens and on cylinders of $D=7 \mathrm{~mm}, h=21 \mathrm{~mm}$ for asphaltites) modes were adopted for the high $\left(20-70{ }^{\circ} \mathrm{C}\right.$ for pure and modified bitumens and $90-140{ }^{\circ} \mathrm{C}$ for asphaltites) and the low $\left(-10-20{ }^{\circ} \mathrm{C}\right.$ for pure and modified bitumens and -10 $90{ }^{\circ} \mathrm{C}$ for asphaltites) temperature domains, respectively. Sinusoidal loading with frequencies from 1 to $80 \mathrm{~Hz}$ for pure and modified bitumens and from 1 to $55 \mathrm{~Hz}$ for asphaltites were applied. In order to be in the linear domain, a displacement of $5 \mu \mathrm{m}$ was chosen in all the experiments except traction-compression tests on asphaltites where a displacement of $3 \mu \mathrm{m}$ was applied.

The complex shear modulus, obtained by annular shearing, is converted to complex traction-compression modulus by applying a Poisson's ratio of 0.5 , thus considering the bitumen as an incompressible material above $20{ }^{\circ} \mathrm{C}$. Master curves, constructed by means of the LCPC method (Chailleux et al. 2006) are presented in Fig. 1. The shift factors, presented in the supplementary information of this paper, follow the WLF rule.

The asphaltite is much harder and behaves much more elastically than the P50/70 petroleum bitumen. For example, at $T=140{ }^{\circ} \mathrm{C}$ and $f=25 \mathrm{~Hz}$, the $\left|E^{*}\right|$ and the $\delta$ for the asphaltite vs. petroleum bitumen are respectively 149,144 vs. $6.67 \mathrm{~Pa}$ and 62.2 vs. $90^{\circ}$. Modified bitumens present intermediate behaviors (Fig. 1). 
(a)

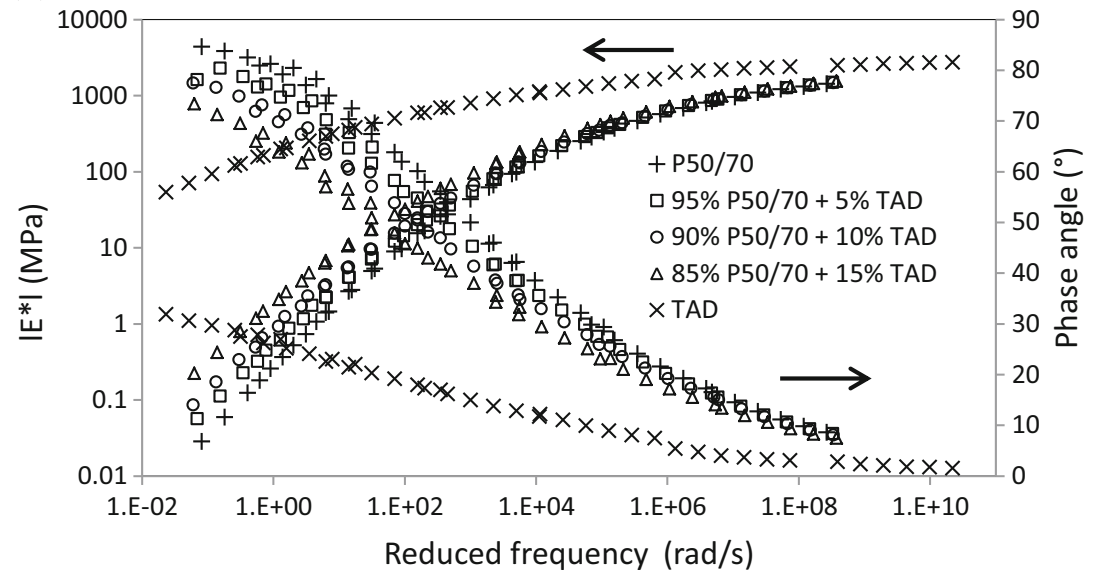

(b)

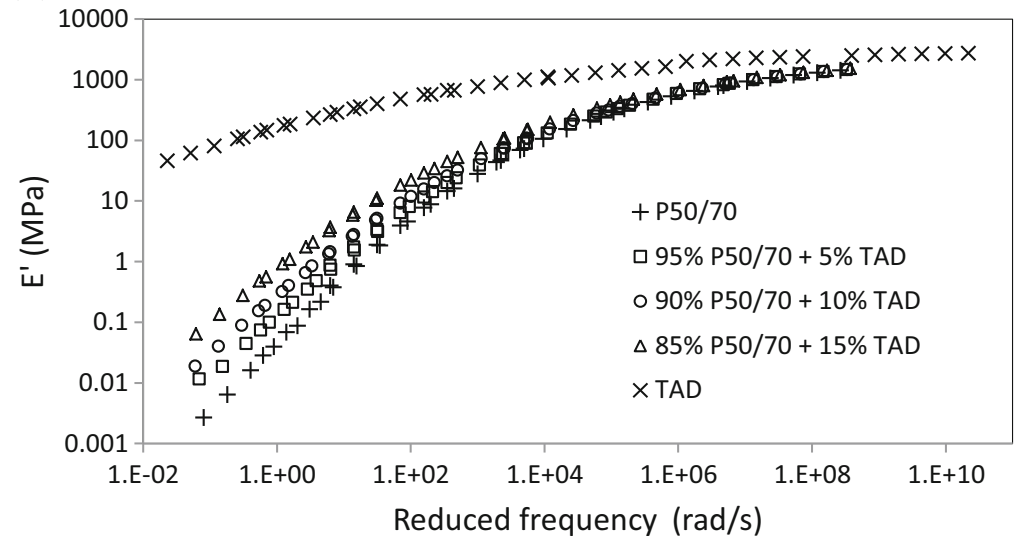

(c)

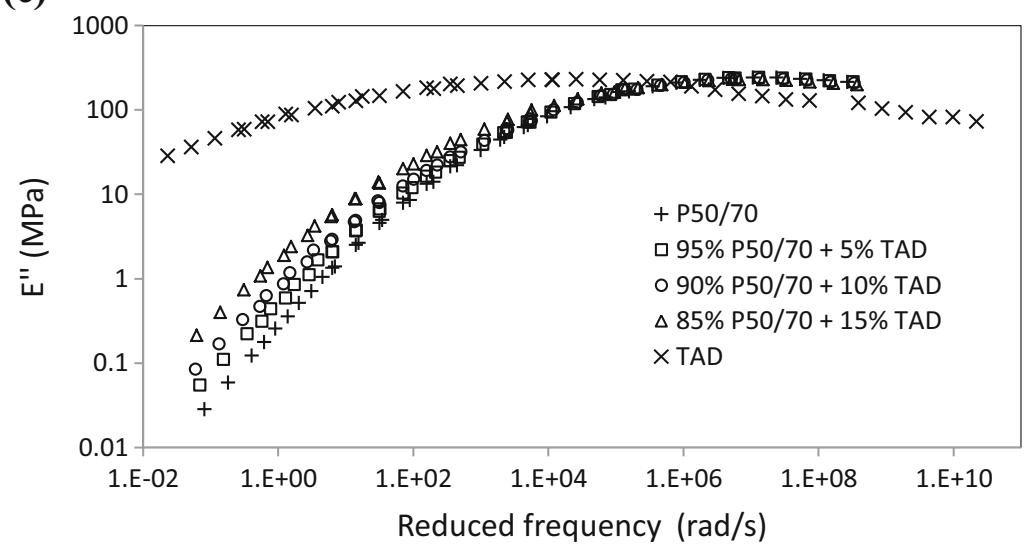

Fig. 1 Master curves of a complex modulus norm and complex modulus phase angle, $\mathbf{b}$ storage modulus, and $\mathbf{c}$ loss modulus of petroleum, modified, and natural bitumens. $T_{\text {ref }}=30^{\circ} \mathrm{C}$

\section{Differential calorimetry}

Thermic behavior of our bitumens was determined by modulated differential scanning calorimetry. The tests were carried out on a TA Instrument of type DSC Q100. Sealed pans were used to encapsulate around $10 \mathrm{mg}$ of sample. After stabilization at $25{ }^{\circ} \mathrm{C}$, the sample is heated to $180{ }^{\circ} \mathrm{C}$ at $10^{\circ} \mathrm{C} / \mathrm{min}$.
Next, it is cooled down to $40{ }^{\circ} \mathrm{C}$ at $10{ }^{\circ} \mathrm{C} / \mathrm{min}$, then down to $-40{ }^{\circ} \mathrm{C}$ at $1{ }^{\circ} \mathrm{C} / \mathrm{min}$, and finally down to $-80{ }^{\circ} \mathrm{C}$ at $5{ }^{\circ} \mathrm{C} / \mathrm{min}$. Next, applying a modulated ramp of $5{ }^{\circ} \mathrm{C} / \mathrm{min}$ with an oscillation period of $60 \mathrm{~s}$ and amplitude $\pm 0.80{ }^{\circ} \mathrm{C}$, the heat flows were measured up to $160{ }^{\circ} \mathrm{C}$.

All the bitumens considered here present wide glass transitions which superpose (Fig. 2). The range between the onset 


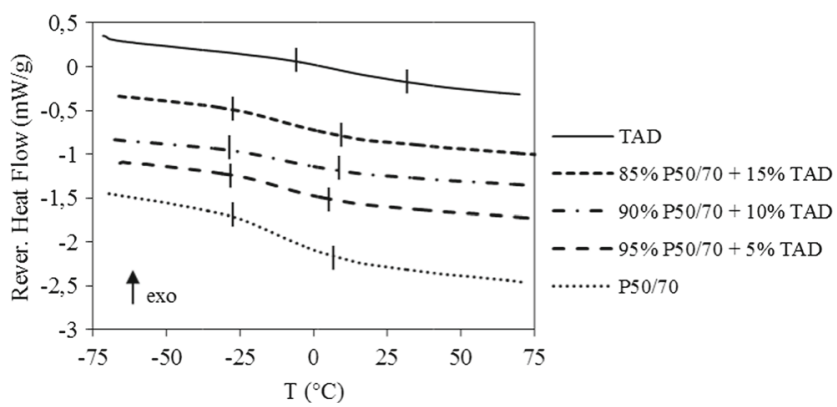

Fig. 2 Reversible heat flow curves of petroleum, modified, and natural bitumens

and the completion of the glass transition is $\Delta T_{g} \approx 30^{\circ} \mathrm{C}$ for all samples. The glass transition temperatures of the asphaltite and of P50/70 bitumen, measured at the inflection point of the reversible heat flow curve, are respectively 8 and $-12^{\circ} \mathrm{C}$. The $T_{g} \mathrm{~S}$ of components are not distinguishable in the heat flow curves of bitumen blends (Fig. 2). Considering the above, we assume that both materials have similar glass transitions. Consequently, we do not apply any temperature shift due to the differences of $T_{g}$ values of pure components of our blends.

\section{Discussion}

\section{Classic blending laws}

Equations 3 and 4 are applied to our measurements in order to predict the linear viscoelastic properties of our blends from the respective properties of pure constituents. As shown in Fig. 3, the prediction is not accurate. Deviations from the classic blending rule confirm the results of (Soleymani et al. 1999) for blends of bitumens of very different consistencies. The observation of the results shows that both storage and loss

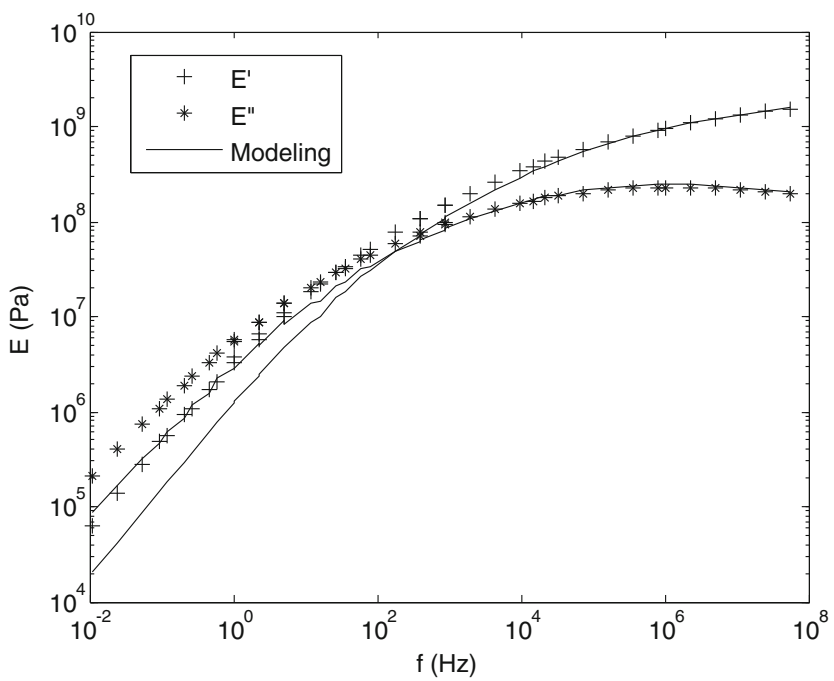

Fig. 3 Blend of 50/70 petroleum paraffinic bitumen with $15 \%$ of asphaltite $(85 \%$ P50/70 + $15 \%$ TAD). Prediction of classic blending law (Eqs. 3 and 4) vs. measurements. $T_{\text {ref }}=30^{\circ} \mathrm{C}$

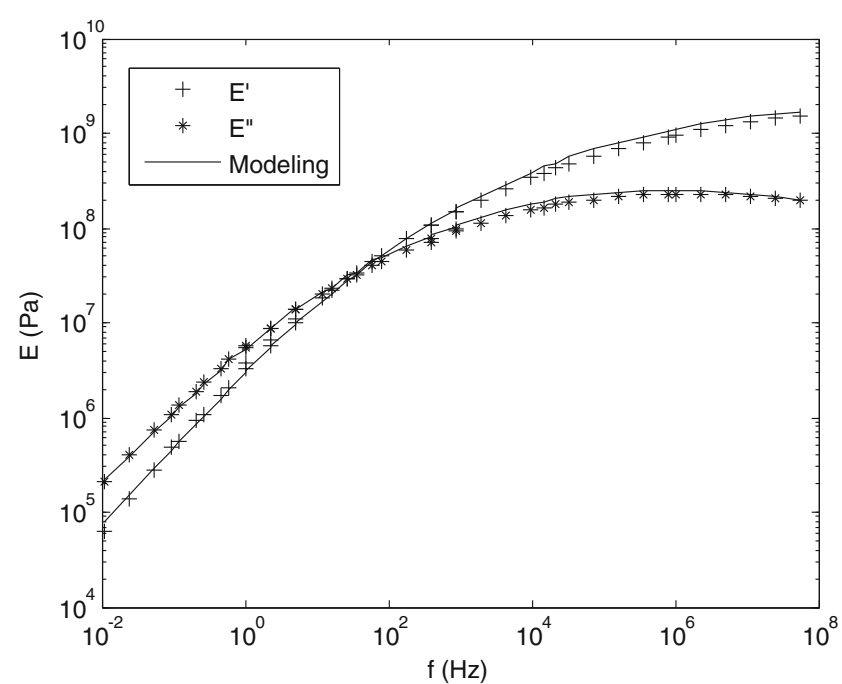

Fig. 4 Blend of 50/70 petroleum paraffinic bitumen with $15 \%$ of asphaltite $(85 \%$ P50/70 $+15 \%$ TAD). Prediction of corrected classic blending law (Eqs. 17 and 18) vs. measurements. $T_{\text {ref }}=30^{\circ} \mathrm{C}$

moduli present a similar order of prediction error. This would suggest that the same correction factor applied to both storage and loss moduli would allow to obtain an accurate prediction.

A correction factor $k$ is applied to Eqs. 3 and 4 which yields:

$\log \left|E_{b}^{*}(\omega, T)\right|=\log \left|E_{B}^{*}(\omega, T)\right|+k \cdot x \cdot\left(\log \left|E_{A}^{*}(\omega, T)\right|-\log \left|E_{B}^{*}(\omega, T)\right|\right)$

$\delta_{b}(\omega, T)=\delta_{B}(\omega, T)+k \cdot x \cdot\left(\delta_{A}(\omega, T)-\delta_{B}(\omega, T)\right)$

The notations are the same as them of Eqs. 3 and 4.

Applying Eqs. 17 and 18 to the experimental measurements, we have adjusted the correction factor. The adjustment is carried out by an error minimization procedure applied simultaneously on the complex modulus norm and the complex modulus phase angle data. The modeling is very satisfactory (Fig. 4). The adjusted correction factors of all blends are resumed in Table 2 with the sum of relative errors (SRE) before and after correction.

It is interesting to remark that the correction factor is unique for all viscoelastic properties, i.e., the same correction factor serves to correct the complex modulus norm, the phase angle, the storage, and loss moduli. This means that the correction factor describes a unique physical phenomenon reflected in all linear viscoelastic properties.

\section{Application of the Tsenoglou model to asphaltite-modified bitumens}

Making the hypothesis that the petroleum bitumens and the natural bitumens are miscible and obey the Tsenoglou assumptions, we have applied the Tsenoglou model to our measurements in order to predict the linear viscoelastic properties 
Table 2 Correction factors and modeling improvement

\begin{tabular}{|c|c|c|c|c|c|}
\hline \multirow[t]{2}{*}{ Blend } & \multicolumn{2}{|c|}{ Without correction factor } & \multicolumn{3}{|c|}{ With correction factor } \\
\hline & $\operatorname{SRE}\left|E_{b}^{*}\right|$ & $\operatorname{SRE} \delta_{b}$ & $k$ & $\operatorname{SRE}\left|E_{b}^{*}\right|$ & $\operatorname{SRE} \delta_{\mathrm{b}}$ \\
\hline $95 \% \mathrm{P} 50 / 70+5 \% \mathrm{TAD}$ & 4.1054 & 1.5448 & 1.702 & 1.1221 & 0.7366 \\
\hline $90 \% \mathrm{P} 50 / 70+10 \% \mathrm{TAD}$ & 5.4870 & 2.7521 & 1.469 & 2.0752 & 1.7059 \\
\hline $85 \% \mathrm{P} 50 / 70+15 \% \mathrm{TAD}$ & 12.177 & 5.2770 & 1.845 & 3.3333 & 1.8388 \\
\hline $95 \%$ NP50/70 + $5 \%$ TAD & 6.9325 & 2.5923 & 2.117 & 1.6727 & 0.6978 \\
\hline $90 \%$ NP50/70 + $10 \%$ TAD & 10.716 & 3.3590 & 1.893 & 2.3718 & 0.7287 \\
\hline $85 \%$ NP50/70 + $15 \%$ TAD & 11.591 & 4.2257 & 1.645 & 2.3464 & 1.0044 \\
\hline $95 \% \mathrm{P} 35 / 50+5 \% \mathrm{TAD}$ & 8.4549 & 1.3412 & 2.382 & 4.3221 & 1.3108 \\
\hline $90 \% \mathrm{P} 35 / 50+10 \% \mathrm{TAD}$ & 9.0228 & 1.6406 & 1.656 & 4.3594 & 1.6565 \\
\hline
\end{tabular}

$* \mathrm{SRE}=\sum_{i=1}^{n}\left(\left|y_{i}^{\text {experimental }}-y_{i}^{\text {model }}\right| / y_{i}^{\text {experimental }}\right)$

of our blends from the respective properties of pure constituents.

Measurements performed in the same temperaturefrequency couples, according to Eqs. 19 and 20, were input to the model and the results were compared to the model output in Fig. 5.

$$
\begin{aligned}
& G_{b}^{\prime}(\omega, T) \cong \phi_{1}^{2} \cdot G_{1}^{\prime}(\omega, T)+\phi_{2}^{2} \cdot G_{2}^{\prime}(\omega, T) \\
& +\frac{8 \cdot \phi_{1} \cdot \phi_{2} \cdot G_{1}^{\prime}(\omega, T) \cdot G_{2}^{\prime}(\omega, T)}{G_{1}^{\prime}(\omega, T)+2 \cdot G_{1}^{\prime}(\omega, T)^{\frac{1}{2}} \cdot G_{2}^{\prime}(\omega, T)^{\frac{1}{2}}+G_{2}^{\prime}(\omega, T)} \\
& G_{b}^{\prime \prime}(\omega, T) \cong \phi_{1}^{2} \cdot G_{1}^{\prime \prime}(\omega, T)+\phi_{2}^{2} \cdot G_{2}^{\prime \prime}(\omega, T) \\
& +\frac{4 \cdot \phi_{1} \cdot \phi_{2} \cdot G_{1}^{\prime \prime}(\omega, T) \cdot G_{2}^{\prime \prime}(\omega, T)}{G_{1}^{\prime \prime}(\omega, T)+G_{2}^{\prime \prime}(\omega, T)}
\end{aligned}
$$

The prediction appears to be very accurate in the low temperature domain (lower than $20^{\circ} \mathrm{C}$ ) and it declines with increasing the temperature (decreasing the frequency). The accuracy decline is particularly visible on the storage modulus.

\section{Application of the Palierne model to asphaltite-modified bitumens}

In a first time, we have applied the Palierne model in order to study the mechanical behavior of the interface. For this, each interfacial tension component was calculated considering the other components as equal to zero. This way of proceeding does not take into account an eventual simultaneous contribution of different components but allows a first approximation of the interface behavior.

The results presented in Fig. 6a show that $\alpha / R$ is not a real constant as it is reported for emulsions but a complex function of temperature and frequency. A complex isotropic interfacial tension is an incorrect back-calculation, yielding from the suppression of the harmonic components of the interfacial tension. $\beta^{\prime}(\omega)$ and $\beta^{\prime \prime}(\omega)$, presented in Fig. 6b and Fig. 6c, respectively, are continuous complex functions of temperature and frequency, indicating that the interface presents a viscoelastic behavior. These results seem to show that materials are not immiscible and an interphase is created between the asphaltite droplets and the petroleum bitumen matrix. This interphase would be responsible of the interfacial mechanical behavior observed in Fig. 6.

For polymer-modified bitumen, the isotropic interfacial tension is of order $\approx 10 \mu \mathrm{N} / \mathrm{m}$ (Lesueur et al. 1998). For an interfacial tension equal to $10 \mu \mathrm{N} / \mathrm{m}$, the particle size would be of order $0.1 \mathrm{~nm}$ in order to obtain a Laplace pressure $(\alpha / R)$ similar in intensity with the lowest observed values for the modulus, i.e., $100 \mathrm{kPa}$ (Fig. 1). So, it is very probable that given the low interfacial tension of the system, no interfacial relaxation would occur in the considered experimental



Fig. 5 Blend of 50/70 petroleum paraffinic bitumen with $10 \%$ of asphaltite $(90 \%$ P50/70 + $10 \%$ TAD). Prediction of the Tsenoglou model (Eqs. 19 and 20) vs. measurements. $T_{\text {ref }}=30^{\circ} \mathrm{C}$ 
(a)

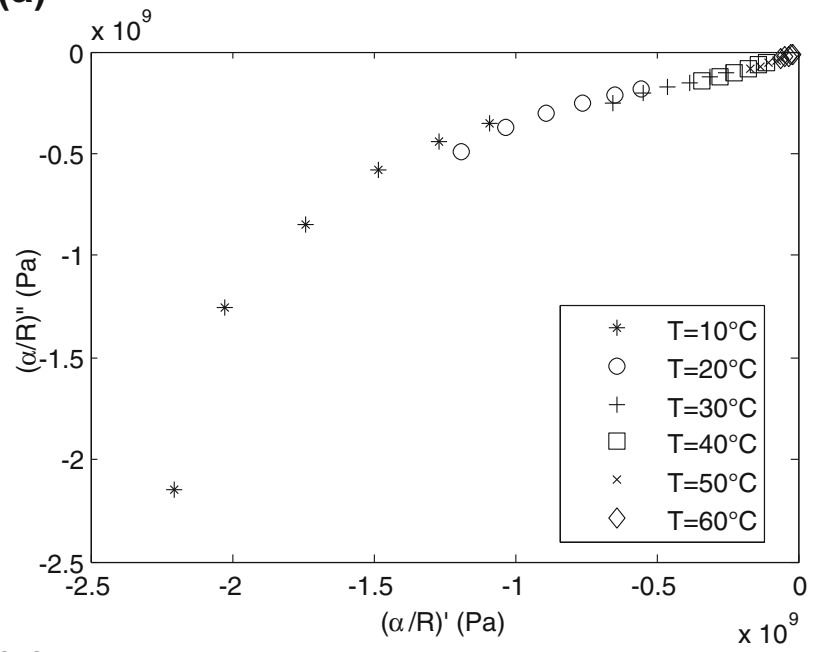

(b)

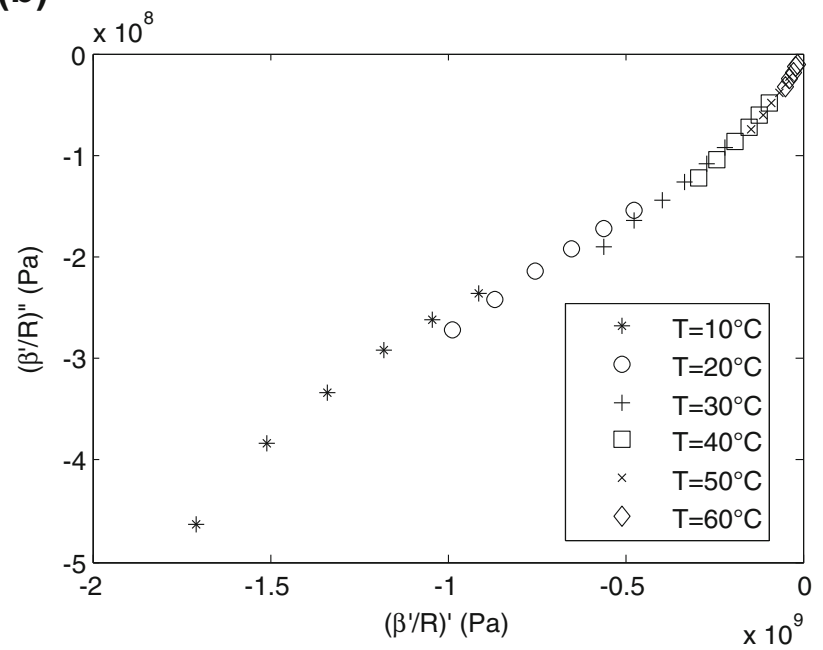

(c)

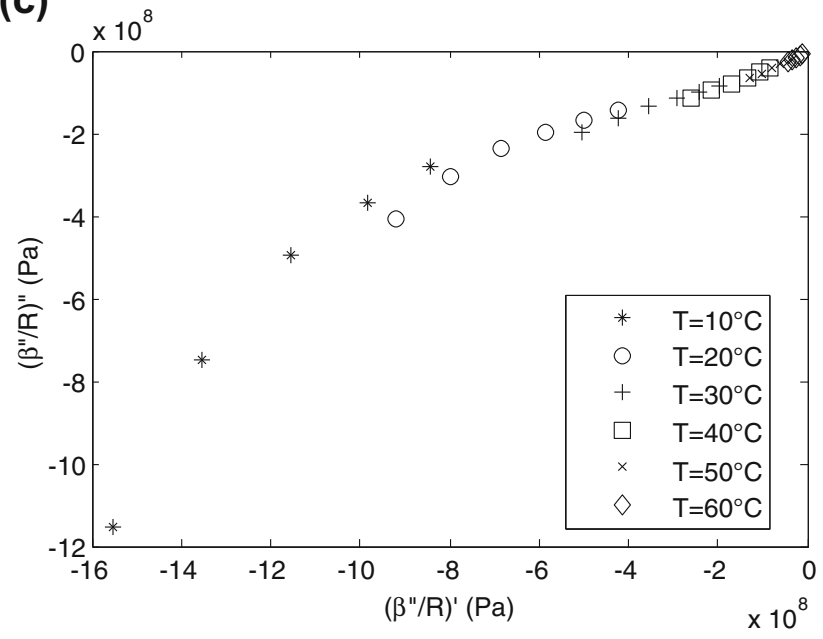

Fig. 6 Cole-Cole curve of $\mathbf{a} \alpha / R, \mathbf{b} \beta^{\prime} / R$, and $\mathbf{c} \beta^{\prime \prime} / R$ parameters of a blend of 50/70 petroleum paraffinic bitumen with $10 \%$ of asphaltite $(90 \%$ P50/ $70+10 \%$ TAD)

measurement range. The interfacial relaxation due to $\alpha$ would manifest for much lower measurement

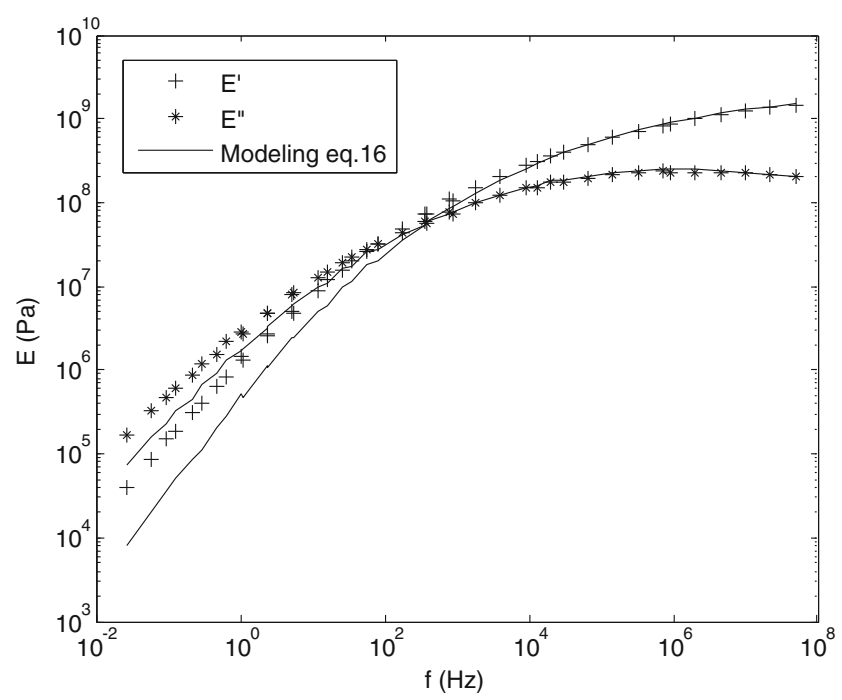

Fig. 7 Blend of 50/70 petroleum paraffinic bitumen with $10 \%$ of asphaltite $(90 \%$ P50/70 + $10 \%$ TAD). Prediction of the Dickie model (Eq. 16) vs. measurements. $T_{\text {ref }}=30^{\circ} \mathrm{C}$

frequencies. The relaxations due to $\beta^{\prime}$ and $\beta^{\prime \prime}$ would be detectable for even lower frequencies (Riemann et al. 1997). Therefore, it looks like that the interfacial tension equal to zero $\left(\alpha=0, \beta^{\prime}=0\right.$, and $\left.\beta^{\prime \prime}=0\right)$, would be a correct assumption for applying the Palierne model to our system.

With interfacial contributions equal to zero, the Palierne model reduces to the Dickie's result for viscoelastic systems (Eq. 16). The prediction of the Dickie model, presented in Fig. 7, underestimates the experimental observations which may indicate that additional mechanisms participate to the mechanical response of the system.

\section{Combination of the Tsenoglou and Dickie models for asphaltite-modified bitumens}

Tsenoglou points out that his model may be employed for the study of partially miscible blends (Tsenoglou 1988a). He suggests to use his molecular approach for the description of each of the homogenous phases in which both components are in miscible state, and then to combine these individual results



Fig. 8 Evolution of inclusions during the modifying process, schematization 
Table 3 Inter-diffusion parameter adjusted from the proposed combination of the Tsenoglou and Dickie models

\begin{tabular}{ll}
\hline Reference & $\phi_{1}$ \\
\hline $95 \% \mathrm{P} 50 / 70+5 \% \mathrm{TAD}$ & 0.203 \\
$90 \% \mathrm{P} 50 / 70+10 \% \mathrm{TAD}$ & 0.250 \\
$85 \% \mathrm{P} 50 / 70+15 \% \mathrm{TAD}$ & 0.209 \\
$95 \% \mathrm{NP} 50 / 70+5 \% \mathrm{TAD}$ & 0.158 \\
$90 \% \mathrm{NP} 50 / 70+10 \% \mathrm{TAD}$ & 0.192 \\
$85 \% \mathrm{NP} 50 / 70+15 \% \mathrm{TAD}$ & 0.235 \\
$95 \% \mathrm{P} 35 / 50+5 \% \mathrm{TAD}$ & 0.155 \\
$90 \% \mathrm{P} 35 / 50+10 \% \mathrm{TAD}$ & 0.230 \\
\hline
\end{tabular}

with a suitable continuum model in order to allow the description of the multiphase blend as a whole. Following these ideas, Lee et.al proposed a hybrid approach coupling the Tsenoglou combination rule with the Palierne model in order to estimate the interfacial tension in partially miscible polymer mixtures (Lee \& Denn 2000, Lee \& Kim 2005). They deduced the phases' inter-diffusions from differential scanning calorimetry and based on these results they calculated the fractions of dispersed and matrix phases and the fractions of each component in each of the phases. However, in our case, such a calculation is impossible because, as stated before, the glass transitions or other thermic events of the components are not distinguishable in the heat flow curves of bitumen blends.

Because of the lack of contrast between the materials, we were not able to define the morphological features of our asphaltite/petroleum-bitumen blends. As a consequence, we could not establish the miscibility degree between the components (miscible, partially miscible, or immiscible?). However, it seems logical to hypothesize that, once the grinded asphaltite is introduced into the petroleum-bitumen matrix, an emulsion-type system of asphaltite inclusions dispersed in the petroleum-bitumen matrix is obtained. The fact that the two materials have very accentuated differences of viscoelastic behavior supports this scenario. During the mixing, the asphaltite is gradually solubilized into the petroleum bitumen, dispersed inclusions absorbing matrix material and increasing their size. The system would gradually evolve from an emulsion-type to a miscible one, the asphaltite/ petroleum-bitumen interface expanding and after some time disappearing (schematization in Fig. 8). Making the additional assumptions that:

a. The system remains a dispersion of modified inclusions in a petroleum-bitumen matrix

b. Inside the inclusions, the asphaltite and the petroleum bitumen are miscible

c. The inclusions have the same asphaltite/petroleumbitumen constitution

d. During the modification process, the matrix properties do not alter

e. The system is monodisperse

and combining the Dickies and Tsenoglou models as detailed below, we can calculate a miscibility factor which would allow an estimation of the miscibility degree between the phases.

Considering the materials inside the inclusions as miscible, their complex modulus can be calculated by the Tsenoglou rule (Eqs. 19 and 20) in which $\phi_{1}$ denotes the fraction of asphaltite in inclusions and $\phi_{2}=1-\phi_{1}$ denotes the fraction of the petroleum bitumen in inclusions. In the context of our hypotheses, $\phi_{1}$ expresses the inter-diffusion of phases or, in other words, the miscibility degree between them. The fraction of modified inclusions in the system is:

$\phi^{\prime}=\frac{\phi}{\phi_{1}}$

where $\phi$ is the fraction of asphaltite in the system.

Based on the discussion of the previous paragraph, null interfacial contributions can be justified and the Dickie model (Eq. 16) can be used to model the system as a whole. Mathematically, the problem is formalized as follows:

$$
\left\{\begin{array}{c}
G_{b}^{*}(\omega, T)=G_{B}^{*}(\omega, T) \frac{\left[2 G_{I}^{*}(\omega, T)+3 G_{B}^{*}(\omega, T)\right]+3 \frac{\phi}{\phi_{1}}\left[G_{I}^{*}(\omega, T)-G_{B}^{*}(\omega, T)\right]}{\left[2 G_{I}^{*}(\omega, T)+3 G_{B}^{*}(\omega, T)\right]-2 \frac{\phi}{\phi_{1}}\left[G_{I}^{*}(\omega, T)-G_{B}^{*}(\omega, T)\right]} \\
G_{I}^{*}(\omega, T)=\phi_{1}^{2} \cdot G_{A}^{\prime}(\omega, T)+\left(1-\phi_{1}\right)^{2} \cdot G_{B}^{\prime}(\omega, T)+\frac{8 \cdot \phi_{1} \cdot\left(1-\phi_{1}\right) \cdot G_{A}^{\prime}(\omega, T) \cdot G_{B}^{\prime}(\omega, T)}{G_{A}^{\prime}(\omega, T)+2 \cdot G_{A}^{\prime}(\omega, T)^{\frac{1}{2}} \cdot G_{B}^{\prime}(\omega, T)^{\frac{1}{2}}+G_{B}^{\prime}(\omega, T)}+ \\
+i\left(\phi_{1}^{2} \cdot G_{A}^{\prime \prime}(\omega, T)+\left(1-\phi_{1}\right)^{2} \cdot G_{B}^{\prime \prime}(\omega, T)+\frac{4 \cdot \phi_{1} \cdot\left(1-\phi_{1}\right) \cdot G_{A}^{\prime \prime}(\omega, T) \cdot G_{B}^{\prime \prime}(\omega, T)}{G_{A}^{\prime \prime}(\omega, T)+G_{B}^{\prime \prime}(\omega, T)}\right)
\end{array}\right.
$$


where:

$\begin{array}{ll}G_{b}^{*} & \begin{array}{l}\text { Complex modulus of the blend } \\ \text { Complex modulus of modified } \\ G_{I}^{*}\end{array} \\ G_{B}^{*}=G_{B}^{\prime}+i \cdot G_{B}^{\prime \prime} & \begin{array}{l}\text { Complex modulus of petroleum } \\ \text { Storage and loss moduli of } \\ G_{B}^{\prime}, G_{B}^{\prime \prime}\end{array} \\ G_{A}^{\prime}, G_{A}^{\prime \prime} & \begin{array}{l}\text { petroleum } \\ \text { Storage and loss moduli of } \\ \text { asphaltite }\end{array} \\ \phi_{1} & \begin{array}{l}\text { The fraction of asphaltite in inclusions } \\ \text { The fraction of asphaltite in the blend }\end{array} \\ \phi & \end{array}$

We have adjusted the inter-diffusion parameter $\phi_{1}$ (which is the only unknown of our problem), and the results for all the studied blends are summarized in Table 3. The adjustment of $\phi_{1}$ is carried out by an error minimization procedure simultaneously applied on the complex modulus norm and on the complex modulus phase angle data. The modeling quality is very satisfactory (Fig. 9). Modeling vs. experimental measurements of other blends are presented in the supplementary information of this paper.

We note that the values of $\phi_{1}$ in Table 3 is comprised between 0 and 1 as expected. The values are of similar order of magnitude, and this may be related to the mixing conditions which are identical for all considered blends. However, in most of the cases, the fraction of asphaltite in the inclusions $\left(\phi_{1}\right)$ increases with the asphaltite content in the blend.

The results obtained by the proposed approach do not contradict the calculation hypotheses. These results suggest a partial miscibility between the phases. The values of $\phi_{1}$ can be used to characterize the miscibility of the blend. However, it is unlikely that these values have fundamental physical meaning, i.e., corresponding to the real fraction of asphaltite in the inclusions.

The dotted lines in Fig. 9 give the response of the proposed combination of models for $\pm 20 \%$ deviation from the adjusted value of $\phi_{1}$. Twenty percent is the maximum relative standard deviation of values of $\phi_{1}$ observed in a group of three blends of the same petroleum bitumen with 5, 10, and $15 \%$ of asphaltite. The $\pm 20 \%$ deviations show that the approach can be used for prediction purposes with an acceptable level of error. So, the assumption of an average value for the $\phi_{1}$ would give satisfactory results for the prediction of linear viscoelastic properties of blends based on the initial properties of pure constituents and their fractions in the blend. In practical terms, this means that the approach can be used for dosage purposes after a preliminary calibration of $\phi_{1}$.



Fig. 9 Blends of 30/50 petroleum paraffinic bitumen with $10 \%$ of asphaltite. Prediction of the proposed combination of models vs. measurements. $T_{\text {ref }}=30^{\circ} \mathrm{C}$

\section{Conclusions}

The work presented in this paper constitutes a basis for further discussion on bitumen blends, asphaltite-modified bitumens, and polymer-modified bitumens.

The proposed approach allows an accurate prediction of the linear viscoelastic behavior of asphaltitemodified bitumens based on the linear viscoelastic properties of pure constituents and as a consequence, it can be used for dosage purposes in order to obtain asphaltite-modified bitumens with predefined viscoelastic properties.

The interpretation of the results suggests a partial miscibility between the asphaltite and petroleum bitumens which is probable considering the fact that both components are chemically similar and they present an accentuated difference of linear viscoelastic properties. However, any experimental prove would be necessary to validate this conclusion. Future experimental work may focus on the incidence of different factors (like the asphaltite grain size, the mixing temperature and duration, the curing time) in the inter-diffusion parameter.

The proposed approach seems adequate for the study of polymer-modified bitumens, of reclaimed asphalt-modified bitumens as well as of partially miscible polymer blends presenting suspended droplet morphology.

Acknowledgments The authors express their gratitude to EPSILON Ingénierie Company and its president Mr. Jean-Louis Duchez for providing the materials and the financial support of this work. In addition, the authors express their gratitude to the reviewers for the careful consideration of this study and the pertinent remarks which allowed improving the quality of this contribution. 


\section{References}

Al-Qadi IL, Elseifi M. \& Carpenter, S. H. (2007), Reclaimed asphalt pavement-a literature review, Technical report, Illinois Center for Transportation

Bardesi A, Brûlé B, Corté J-F (1999), Use of modified bituminous binders, special bitumens and bitumens with additives in road pavements, Technical report, World Road Association (PIARC)

Bearsley S, Forbes A, Haverkamp RG (2004) Direct observation of the asphaltene structure in paving-grade bitumen using confocal laserscanning microscopy. J Microsc 215(2):149-155. doi:10.1111 /j.0022-2720.2004.01373.x

Bousmina M (1999) Rheology of polymer blends: linear model for viscoelastic emulsions. Rheol Acta 38(1):73-83. doi:10.1007 /s003970050157

Bousmina M, Muller R (1993) Linear viscoelasticity in the melt of impact pmma. Influence of concentration and aggregation of dispersed rubber particles. Journal of Rheology (1978-present) 37(4):663-679 http://scitation.aip.org/content/sor/journal/jor2/37/4/10.1122 $/ 1.550389$

Brahimi B, Ait-Kadi A, Ajji A, Jérôme R, Fayt R (1991) Rheological properties of copolymer modified polyethylene/polystyrene blends. Journal of Rheology (1978-present) 35(6):1069-1091 http://scitation.aip.org/content/sor/journal/jor2/35/6/10.1122 1.550166

Brodnyan JG, Gaskins FH, Philippoff W, Thelen E (1960) The rheology of asphalt. iii. Dynamic mechanical properties of asphalt. Transactions of The Society of Rheology (1957-1977) 4(1):279 $296 \mathrm{http}: / /$ scitation.aip.org/content/sor/journal/tsor/4/1/10.1122 $/ 1.548858$

Chailleux E, Ramond G, Such C, de La Roche C (2006) A mathematicalbased master-curve construction method applied to complex modulus of bituminous materials. Road Materials and Pavement Design 7(sup1):75-92. doi:10.1080/14680629.2006.9690059

Choi SJ, Schowalter WR (1975) Rheological properties of nondilute suspensions of deformable particles. Physics of Fluids (1958-1988) 18(4):420-427 http://scitation.aip.org/content/aip/journal/pof1/18 /4/10.1063/1.861167

Des Cloizeaux J (1990) Relaxation of entangled polymers in melts. Macromolecules 23(17):3992-4006. doi:10.1021/ma00219a021

Dickie RA (1973) Heterogeneous polymer-polymer composites. i. Theory of viscoelastic properties and equivalent mechanical models. J Appl Polym Sci 17(1):45-63. doi:10.1002/app.1973.070170104

Doi M, Edwards S (1986) The theory of polymer dynamics, international series of monographs on physics, Clarendon Press. http://books. google.fr/books?id=h-PvAAAAMAAJ

Dwiggins CW (1965) A small angle x-ray scattering study of the colloidal nature of petroleum. J Phys Chem 69(10):3500-3506. doi:10.1021 /j100894a041

Florian H, Josef F, Susanna N, Daniel G, Lukas E, Bernhard H, Markus H, Ronald B, Hinrich G (2014) Understanding the microstructure of bitumen: a CLSM and fluorescence approach to model bitumen ageing behavior. In: Asphalt Pavements, p. 521-530

Friedrich C, Gleinser W, Korat E, Maier D, Weese J (1995) Comparison of sphere-size distributions obtained from rheology and transmission electron microscopy in PMMA/PS blends. Journal of Rheology (1978-present) 39(6):1411-1425 http://scitation.aip. org/content/sor/journal/jor2/39/6/10.1122/1.550720

Frohlich H, Sack R (1946) Theory of the rheological properties of dispersions. Proceedings of the Royal Society of London A: Mathematical, Physical and Engineering Sciences 185(1003): 415-430

Gell C, Krishnamoorti R, Kim E, Graessley W, Fetters L (1997) Viscoelasticity and diffusion in miscible blends of saturated hydrocarbon polymers. Rheol Acta 36(3):217-228. doi:10.1007 /BF00366662

Graebling D, Muller R (1990) Rheological behavior of polydimethylsiloxane/polyoxyethylene blends in the melt. Emulsion model of two viscoelastic liquids. Journal of Rheology (1978-present) 34(2):193-205 http://scitation.aip. org/content/sor/journal/jor2/34/2/10.1122/1.550123

Graebling D, Muller R, Palierne JF (1993) Linear viscoelastic behavior of some incompatible polymer blends in the melt. Interpretation of data with a model of emulsion of viscoelastic liquids. Macromolecules 26(2):320-329. doi:10.1021/ma00054a011

Graebling D, Benkira A, Gallot Y, Muller R (1994) Dynamic viscoelastic behaviour of polymer blends in the melt - experimental results for PDMS/POE-DO, PS/PMMA and PS/PEMA blends. Eur Polym J 30 ( 3 ): $301-308$ h t t p://www. sciencedirect. com/science/article/pii/0014305794902909

Groves DJ, McLeish TC, Chohan RK, Coates PD (1996) Predicting the rheology of linear with branched polyethylene blends. Rheol Acta 35(5):481-491. doi:10.1007/BF00368998

Hadrzynski F, Such C (1998) Modélisation du comportement rhéologique des bitumes polymères - le modèle autocohérent. Bulletin des laboratoires des ponts et chaussées No. 214:3-18

Haley JC, Lodge TP (2004) A framework for predicting the viscosity of miscible polymer blends. J Rheol 48(2):463-486 http://scitation.aip. org/content/sor/journal/jor2/48/2/10.1122/1.1647561

Haley JC, Lodge TP, He Y, Ediger MD, von Meerwall ED, Mijovic J (2003) Composition and temperature dependence of terminal and segmental dynamics in polyisoprene/poly(vinylethylene) blends. Macromolecules 36(16):6142-6151. doi:10.1021/ma034414z

Henaut I, Barre L, Argillier J-F, Brucy F, Bouchard R, (2001) Rheological and structural properties of heavy crude oils in relation with their asphaltenes content. In: SPE International Symposium on Oilfield Chemistry, Society of Petroleum Engineers

Jacobs U, Fahrländer M, Winterhalter J, Friedrich C (1999) Analysis of Palierne's emulsion model in the case of viscoelastic interfacial properties. Journal of Rheology (1978-present) 43(6):1495-1509 http://scitation.aip.org/content/sor/journal/jor2/43/6/10.1122 $/ 1.551056$

Kerner EH (1956) The elastic and thermoelastic properties of composite media. Proceedings of The Physical Society Section B 69:808-813

Kim HC, Nam KH, Jo WH (1993) The effect of a styrene-methyl methacrylate block copolymer on the morphological, rheological and mechanical properties of poly(2,6-dimethyl-1,4-phenylene ether) (PPE) and poly(hydroxy ether of bisphenol a) (phenoxy) blends. Polymer 34(19):4043-4051 http://www.sciencedirect. com/science/article/pii/003238619390665W

Lacroix C, Bousmina M, Carreau P, Favis B, Michel A (1996) Properties of PETG/EVA blends: 1. Viscoelastic, morphological and interfacial properties. Polymer 37(14):2939-2947 http://www.sciencedirect. com/science/article/pii/003238619689389X

Lee HS, Denn MM (2000) Blends of linear and branched polyethylenes. Polym Eng Sci 40(5):1132-1142. doi:10.1002/pen.11241

Lee HS, Kim ES (2005) Linear viscoelasticity and the measurement of interfacial tension in a partially miscible polymer mixture. Macromolecules 38(4):1196-1200. doi:10.1021/ma0485179

Lesueur D (2009) The colloidal structure of bitumen: consequences on the rheology and on the mechanisms of bitumen modification. Adv Colloid Interf Sci 145(1-2):42-82 http://www.sciencedirect. com/science/article/pii/S0001868608001413

Lesueur D, Gérard J-F, Claudy P, Létoffé J-M, Martin D, Planche J-P (1998) Polymer modified asphalts as viscoelastic emulsions. Journal of Rheology (1978-present) 42(5):1059-1074 http://scitation.aip.org/content/sor/journal/jor2/42/5/10.1122 11.550918

Loeber L, Sutton O, Morel J, Valleton J-m, Muller G (1996) New direct observations of asphalts and asphalt binders by scanning electron 
microscopy and atomic force microscopy. J Microsc 182(1):32-39. doi:10.1046/j.1365-2818.1996.134416.x

Lu X, Langton M, Olofsson P, Redelius P (2005) Wax morphology in bitumen. J Mater Sci 40(8):1893-1900. doi:10.1007/s10853-005$1208-4$

Mangiafico S, Di Benedetto H, Sauzéat C, Olard F, Pouget S, Planque L (2014) New method to obtain viscoelastic properties of bitumen blends from pure and reclaimed asphalt pavement binder constituents. Road Materials and Pavement Design 15(2):312-329. doi:10.1080/14680629.2013.870639

Masson J-F, Polomark G (2001) Bitumen microstructure by modulated differential scanning calorimetry. Thermochim Acta 374(2):105$114 \mathrm{ht} \mathrm{t}$ p : / / w w w. s c i e n c e d i r e c t. com/science/article/pii/S0040603101004786

Oldroyd JG (1953) The elastic and viscous properties of emulsions and suspensions. Proceedings of the Royal Society of London A: Mathematical, Physical and Engineering Sciences 218(1132):122132

Oldroyd JG (1955) The effect of interfacial stabilizing films on the elastic and viscous properties of emulsions', Proceedings of the Royal Society of London A: Mathematical. Phys Eng Sci 232

Overfield R, Sheu E, Sinha S, Liang K (1989) Sans study of asphaltene aggregation. Fuel Science and Technology International 7(5-6): 611-624. doi:10.1080/08843758908962260

Palierne J (1990, 1991) Linear rheology of viscoelastic emulsions with interfacial tension. Rheol Acta 29(3):204-214. doi:10.1007/BF01331356

Ravey J, Ducouret G, Espinat D (1988) Asphaltene macrostructure by small angle neutron scattering. Fuel 67(11):1560-1567 http://www. sciencedirect.com/science/article/pii/0016236188900762

Riemann R-E, Cantow H-J, Friedrich C (1996) Rheological investigation of form relaxation and interface relaxation processes in polymer blends. Polym Bull 36(5):637-643. doi:10.1007/BF00342457

Riemann R-E, Cantow H-J, Friedrich C (1997) Interpretation of a new interface-governed relaxation process in compatibilized polymer blends. Macromolecules 30(18):5476-5484. doi:10.1021 /ma961814w

Roths T, Friedrich C, Marth M, Honerkamp J (2002) Dynamics and rheology of the morphology of immiscible polymer blends - on modeling and simulation. Rheol Acta 41(3):211-222. doi:10.1007 /s003970100189

Soenen H, Lu X, Redelius P (2008) The morphology of bitumen-SBS blends by UV microscopy. Road Materials and Pavement Design 9(1):97-110. doi:10.1080/14680629.2008.9690109

Soleymani, Hamid R., Bahia, H. \& Bergan, A. (1999), Time-temperature dependency of blended and rejuvenated asphalt binders. In: Annual
Meeting of the Association of Asphalt Paving Technologists, Vol. V.68-99, p. 129

Taylor GI (1932) The viscosity of a fluid containing small drops of another fluid. Proceedings of the Royal Society of London A: Mathematical, Physical and Engineering Sciences 138(834):41-48

Themeli A (2015), Etude du potentiel d'emploi des bitumes naturels dans la production des liants bitumineux durs et des enrobés à module élevé, $\mathrm{PhD}$ thesis, Strasbourg University

Themeli A, Chailleux E, Farcas F, Chazallon C, Migault B, Didelet G (2016) Ageing performances of asphaltite modified bitumens; comparisons with equivalent petroleum bitumens. Springer Netherlands, Dordrecht, pp. 89-101. doi:10.1007/978-94-017-7342-3_8

Ton-That C, Shard A, Teare D, Bradley R (2001) \{XPS $\}$ and $\{$ AFM surface studies of solvent-cast PS/PMMA blends. Polymer 42(3): $1121-1129$ h t t p: // w w w. s c i e n c ed i rect. com/science/article/pii/S0032386100004481

Tsenoglou C (1987) Viscoelasticity of binary homopolymer blends. Polymer Preprints (American Chemical Society, Division of Polymer Chemistry) 28:185-186

Tsenoglou C (1988a) Network architecture and modulus of miscible heteropolymer blends. J Polym Sci B Polym Phys 26:2329-2339

Tsenoglou, C. (1988b), Viscoelasticity and self-diffusion in miscible heteropolymer blends. In: new trends in physics and physical chemistry of polymers

Tsenoglou C (1991) Molecular weight polydispersity effects on the viscoelasticity of entangled linear polymers. Macromolecules 24: 1762-1767

Van Hemelrijck E, Van Puyvelde P, Velankar S, Macosko CW, Moldenaers P (2004) Interfacial elasticity and coalescence suppression in compatibilized polymer blends. Journal of Rheology (1978present) $48(1): 143-158 \mathrm{http}: / / \mathrm{sc}$ itation.aip. org/content/sor/journal/jor2/48/1/10.1122/1.1634987

Vinckier I, Moldenaers P, Mewis J (1996) Relationship between rheology and morphology of model blends in steady shear flow. Journal of Rheology (1978-present) 40(4):613-631 http://scitation.aip. org/content/sor/journal/jor2/40/4/10.1122/1.550800

Vinckier I, Mewis J, Moldenaers P (1997) Stress relaxation as a microstructural probe for immiscible polymer blends. Rheol Acta 36(5): 513-523. doi:10.1007/BF00368129

Whiteoak, D. (1990) The Shell bitumen handbook, 5th edition edn, Shell Bitumen UK

Widyatmoko I, Elliott R (2008) Characteristics of elastomeric and plastomeric binders in contact with natural asphalts. Constr Build Mater 22(3):239-249 http://www.sciencedirect. com/science/article/pii/S0950061806002698 